\title{
Corpos-ouvidos destes tempos: implante coclear na mídia
}

\author{
Bodies-ears of these times: cochlear implant media
}

\author{
Daniela Medeiros* \\ Universidade Regional do Noroeste do Estado do Rio Grande do Sul \\ Maria Simone Vione Schwengber** \\ Universidade Regional do Noroeste do Estado do Rio Grande do Sul
}

Resumo Este artigo apresenta uma reflexão sobre as relações entre mídia e a fabricação dos sujeitos surdos. Do conjunto de materiais, recortamos do Programa Fantástico especificamente o quadro sobre saúde, na reportagem intitulada "Crianças que nasceram surdas escutam pela primeira vez". Tornamos a mídia um campo social a partir das ferramentas teóricas foucaultianas - discursos e sujeitos - analisando textos e imagens, extraindo deles seus enunciados e os regimes de verdade que produzem, de forma minuciosa, com regularidade e suposta legitimidade, um padrão social de referência e correção por meio do implante coclear - corpos-sujeitos-ouvidos - desejável. Ainda é possível perceber a invisibilização da língua de sinais e a produção de discursos que tratam a surdez como uma deficiência, localizada em um lugar de possível correção pelo implante coclear.

PALAVRAS-ChAVE: Implante coclear; Mídia; Surdez.

\begin{abstract}
This article presents a reflection about the relations between the media and the fabrication of deaf citizens. The set of materials, we cut of the program "Fantastic" specifically the presentment of health, story titled "Children that was born deaf hear for the first time". We make the media a social field from Foucault's theoretical tools - speeches and subjects - analyzing texts and images, extracting them their statements and the truth regimes that produce, in detail, on a regular and supposed legitimacy, a social pattern and correction by means of cochlear implants - body-subject-ears - desirable. It is still possible notice the invisibilization of sign language and the production of speeches that treat deafness as a disability, located in a place of possible correction by the cochlear implant.
\end{abstract}

KEYWORDS: Cochlear implant; Media; Deafness. 


\section{Introdução}

Este texto parte de algumas inquietações, interesses, leituras e pesquisas experimentadas na educação de surdos, situando-se dentro de uma pesquisa maior. Dentre as possibilidades de recortes epistemológicos, estes escritos foram constituídos, especialmente, com Foucault e Deleuze, ${ }^{1}$ naquilo que chamamos de filosofias da diferença.

Entendemos a mídia como uma produção cultural contemporânea; uma prática discursiva que produz sistemas de significação e modos de ser, de pensar. Fischer (2012) considera a mídia como produtora de verdades, indicando a necessidade de uma análise que possa nos situar nesse contexto em que o discurso, a imagem, o fato de "ter aparecido na TV", configura poder, produz regimes de verdade com efeitos específicos nas formas de subjetivação, e forja no cotidiano determinados modos de relação que as pessoas estabelecem consigo mesmas.

A contemporaneidade alimenta uma renovada representação da surdez a partir da reconstrução dos corpos-ouvidos, possibilitada pelas biotecnologias, com o aparecimento dos diferentes discursos que se multiplicaram nas políticas públicas, nos tratados médicos, em manuais, assim como nas inúmeras publicações enfatizadas pela mídia. Pode-se se afirmar que a mídia passou a monitorar os corpos, inclusive os surdos, por intermédio de uma rede de informações, dentro daquilo que Schwengber (2006, p. 14) chamou "biopolítica informacional": "[...] uma forma de governo que não depende [apenas] da relação corpo-a-corpo para fazer valer um poder sobre a vida, mas de um conjunto de técnicas e saberes que regulam a vida" por meio das informações.

Do amplo conjunto de materiais informativos veiculados na mídia brasileira, optamos como corpus da investigação pelo Programa Fantástico (programa de TV aberta transmitido nos domingos à noite e vinculado à Rede Globo de Televisão). Escolhemos o primeiro episódio como corpus, que foi ao ar no dia 12 de outubro de 2014, e intitulou-se "Crianças que nasceram surdas escutam pela primeira vez".

A reportagem foi assistida por diversas vezes, e seus discursos, textos, enunciados e imagens, foram transcritas em língua portuguesa, sendo compreendidas como unidades discursivas produtoras de verdades e sentidos. Estas transcrições (corpus do texto) foram problematizadas a partir dos quatro elementos básicos do enunciado descritos por Fischer (2001): "Um referente (ou seja, um princípio de diferenciação), um sujeito (no sentido de 'posição' a ser ocupada), um campo associado (isto é, coexistir com outros enunciados) e uma materialidade específica”(FISCHER, 2001, p. 202).

As ferramentas conceituais foucaultianas utilizadas dizem respeito aos conceitos de corpo, discurso, subjetivação e de artes de governar quando relacionadas às praticas de cuidados de si a partir de certa forma de normalização, que supõe um tipo de ação sobre os corpos-ouvidos-surdos e sobre a gestão da vida e de seus processos. Assim, a ênfase da ação recai sobre a produção de comportamentos e a fabricação de subjetividades. Lançamos, então, como via de desdobramento do problema de pesquisa, a seguinte pergunta: Como o Programa Fantástico, em especial no episódio "Crianças que nasceram surdas escutam pela primeira vez", produz verdades e modos de ser e pensar sobre a surdez? 
Entendemos que tal reportagem é produtora de discursos sobre os surdos, a surdez, a língua de sinais e o implante coclear. Diante disto, objetivamos tencionar tais discursos, considerando-os produtores da diferença surda e dos modos de subjetivação dos surdos mediante as tecnologias de si produzidas, em especial, pelo implante coclear.

$\mathrm{Na}$ busca pela elaboração de possíveis tencionamentos discursivos, a reportagem é analisada e problematizada a partir de três unidades discursivas: Corpos implantados e a possibilidade de amenizar a "falha" (a notícia como via informativa); Casos recortados e o implante coclear como histórias de felicidade; e "Cadê o surdo que estava aqui?" (as (in)visibilidades como linha de apagamento da surdez e da língua de sinais). Nesse sentido, o sujeito é um efeito das relações de saber-poder, assumindo para si uma conduta para que outros também o identifiquem como normal.

Estas unidades são compostas pelo dizível e visível da reportagem em questão, em uma linha de descontinuidade que nos exigiu um olhar atento, cuidadoso e questionador, a fim de localizar, recortar e problematizar aquilo que (não) se diz e (não) se mostra. A perspectiva teórica e metodológica escolhida nos permite tecer elaborações acerca do(s) lugar(es) dos surdos nos discursos midiáticos, daquilo que se associa a tais discursos e desta implicabilidade na constituição subjetiva dos mesmos.

\section{Corpos implantados e a possibilidade de amenizar a "falha" (a notícia como via informativa)}

Ao analisar e questionar os discursos produzidos pela notícia "Crianças que nasceram surdas escutam pela primeira vez", as questões referentes às informações - surdez e necessidade do implante coclear - ganham destaque. Esta unidade enunciativa parece caracterizar-se por uma função informativa, fornecendo dados e depoimentos discursivos, inicialmente dos médicos, acerca do implante coclear.

A notícia produz enunciados sobre os corpos e o implante coclear, tratando de outras formas de existência, de outros modos de vida, de outras possibilidades de ver e dizer do (não) ser surdo, produzindo, assim, regimes de verdades. A notícia funciona como "uma eficiente dobradiça capaz de articular os poderes que aí circulam com os saberes que a enformam e aí se ensinam”(VEIGA-NETO, 2011, p.15).

Tratamos da construção de redes de saber e poder, instaurando modos de subjetivação àqueles que se sentem envolvidos com as questões relacionadas à surdez (especialmente familiares e surdos). A mídia e aquilo que ela veicula e transmite à população, também é entendido aqui como produção discursiva e produção de verdades. Estas verdades, por vezes, parecem apoderar-se da tarefa de caracterizar, classificar, separar e distribuir. Parecem produzir ou mesmo inventar "novos regimes de subjetivação" (ROSE, 2011, p. 59).

Tais ações são alcançadas a partir de discursos legitimados, muitas vezes por aqueles que chamamos de especialistas, ou mesmo de experts. Estes, os experts, veiculam seus discursos por meio da mídia, dando legitimidade àquilo que a reportagem busca transmitir. Assim, os cidadãos (neste caso, os surdos e suas famílias) são "subjetivados, educados e convidados a realizar uma aliança frouxa e flexível entre suas 
interpretações e ambições pessoais e os modos de vida social ou institucionalmente valorizados" (ROSE, 2011, p. 114).

Nesse sentido, os discursos "prometem restaurar o sujeito para a autonomia e a liberdade" (ROSE, 2011, p. 115), fato que é visibilizado quando a informação é apresentada/legitimada pelo(s) especialista(s) da área e, em seguida, visibilizada pelos relatos de crianças implantadas, autônomas e felizes. Além da legitimação dos experts, o que pode implicar maior credibilidade e confiança àquilo que a notícia apresenta, a reportagem também é instaurada na área médica, sem vias de abertura para problematizações de ordem cultural. Aí, o discurso médico é visibilizado por duas vezes, de forma rápida e objetiva, dizendo do que se trata o implante coclear e para quem é indicado.

Em relação ao tempo destinado aos discursos informativos, em sobreposição àqueles que chamamos de relatos/histórias de vida, é absolutamente inferior, ocupando-se de 19 segundos de um total de 4 minutos e 48 segundos (tempo total da notícia), o que resulta em 6,59\% destinado às questões de informação (somente médica) acerca do assunto. Neste sentido, podemos pensar naquilo que se pretende com a notícia: Informar sobre o implante coclear de forma mais detalhada e com diferentes linhas de interpretação/posicionamento sobre o assunto, ou apresentar relatos de sucesso e felicidade do implante, instaurando um regime de convencimento acerca dos benefícios do mesmo?

Quando tratamos de discursos, neste caso midiáticos, compreendemos que "em toda sociedade a produção do discurso é ao mesmo tempo controlada, selecionada, organizada e redistribuída” (FOUCAULT, 2013, p. 8). Nestas tarefas de controlar, selecionar, organizar e redistribuir, o tempo e a visibilidade de cada discurso são distintos, cuidadosamente escolhidos, recortados, descartados, reorganizados de maneira a atender o objetivo principal da notícia. É como se tratássemos de "uma espécie de desnivelamento entre os discursos" (FOUCAULT, 2013, p. 21).

Em uma destas falas, o médico alerta que "- É uma cirurgia de alta complexidade, é uma cirurgia minuciosa”. Sua complexidade e minúcia não se corporificam ou traduzem nas imagens e tampouco nas histórias apresentadas. A informação compõe a notícia, mas de forma tão breve e sobreposta por cenas de reabilitação (ou mesmo de adaptação à condição de ouvinte), que aquilo dito pelos médicos parece ser sufocado pelos relatos dos pais das crianças implantadas.

Mais adiante, e ainda entre cenas e relatos de crianças implantadas, o médico explica que o implante coclear " $-E$ É indicado para pessoas que praticamente não escutam nada e que não se beneficiam com o aparelho de audição convencional”. O enunciado se associa aos discursos acerca das próteses auditivas, comumente utilizadas por deficientes auditivos ou mesmo por pessoas que perderam parte da audição com o passar do tempo. A ideia é de que a tentativa de adaptação ao aparelho auditivo convencional pode, ou deve, ser uma primeira tentativa de correção que, caso não funcione efetivamente, implicará busca pelo implante coclear. 
Tal discurso é elaborado pelo princípio de diferenciação entre indivíduos que conseguem ouvir com o aparelho de audição e aqueles aos quais a alternativa é o implante coclear. Aí, dois modos de subjetivação se fazem perceptíveis: aquele que ocorre de forma mais fácil e móvel, por meio do aparelho de audição, permitindo mutações de corpo e criação de outros modos de vida, e aquele que acontece por meio do implante coclear, o qual dificulta as mudanças corporais e subjetivadoras, uma vez que fixa o sujeito em um modo de vida mais fechado, com menos possibilidade de "respiração".

Aos surdos e suas famílias a notícia informa duas possibilidades de posicionamentos (ou mesmo de um apagamento e invisibilização da surdez): o aparelho auditivo convencional e/ou o implante coclear, posto que o segundo, apesar do informativo de complexidade e minúcia, parece garantir a felicidade em uma vida plena de realizações e com acesso àquilo que chamamos de show da vida.

A centralidade dos discursos informativos se faz, indiscutivelmente, sobre o implante coclear, coexistindo com enunciados de cura, reabilitação, adaptação e possibilidade de uma vida "normal". A fim de oferecer maiores subsídios informativos àqueles que o buscam, a notícia visibiliza na tela uma legenda com um endereço eletrônico no qual há uma relação de hospitais que realizam o implante coclear no Brasil.

Assim, os discursos informativos aparecem de forma breve, objetiva e sem grandes margens para questionamentos ou dúvidas por parte dos telespectadores. A sensação é de que o implante coclear e a decisão pela realização do mesmo ocorreram, em ambos os casos relatados, de forma tranquila e feliz, sem grandes riscos para as crianças. Junto a tudo isto, é informado o endereço, indicando caminhos para que aqueles que assistirem à reportagem sintam-se convidados a invisibilizar seus medos e angústias em torno da surdez, ou, mesmo, sintam-se à vontade para se ajustar aos padrões de normalidade estabelecidos pela sociedade e legitimados pela mídia.

\section{Casos recortados e o implante coclear como histórias de felicidade}

Junto aos discursos informativos, as histórias de crianças implantadas compõem a rede de discursos apresentados e nos permitem outras problematizações. Vale destacar que as mesmas utilizaram-se de 4 minutos e 16 segundos, de um total de 4 minutos e 48 segundos, o que equivale a $88,8 \%$ do tempo destinado aos recortes de histórias de felicidade e sucesso do implante coclear.

As histórias apresentadas fazem a abertura da notícia, trazendo imagens do momento exato em que crianças que nasceram surdas escutam pela primeira vez. $\mathrm{O}$ referente de importância e emoção no momento de descoberta dos sons. A saída de um lugar sem som para "a descoberta das maravilhas que compõem a vida", até então desconhecidas, em razão de sua incapacidade de ouvir. O enunciado se corporifica nas imagens que seguem e acompanham as falas da repórter, dando materialidade a uma ideia de "felicidade", anunciada no início da notícia. 
Um bebê e a experiência de seu primeiro aparelho de audição. A imagem de choro e irritação, logo que o aparelho é colocado, vai sendo substituída por outra na qual o bebê acompanha atentamente aquilo que é falado e, aos poucos, parece demonstrar tranquilidade, paz e alegria. Imagens de um bebê se adaptando ao aparelho e a nova situação que agora se apresenta: condição de ouvinte.

A possibilidade de um filho ouvinte se reflete na fala da mãe: “- Ele está sorrindo!” A mãe sorri. A médica sorri.” A repórter relata sua história, ou mesmo sua conquista e superação: “- Esta foi a primeira vez que o bebê australiano Lachlan, então com dois meses de vida, ouviu a voz dos pais. Ele nasceu surdo e, com a ajuda de um aparelho auditivo, começou a escutar". O princípio de diferenciação foca na felicidade de escutar e na sensação de alívio daqueles que o acompanham.

O implante coclear como linha que invade um corpo de intensidades, um corpo que "é não-desejo, mas também desejo. Não é uma noção, um conceito, mas antes uma prática, um conjunto de práticas” (DELEUZE; GUATTARI, 2012, p. 12). $\mathrm{E}$ aí, quando tudo é retirado, quando a surdez é retirada, o que resta é o $\mathrm{Cs}_{s} \mathrm{O}^{2}$. E o que se retira, aquilo que sai junto com a surdez, "é justamente o fantasma, o conjunto de significâncias e subjetivações”(DELEUZE, GUATTARI, 2012). Deformamos o CsO e suas sensações já não são mais as mesmas.

A história do implante relacionada discursivamente à "descoberta da felicidade" de Lachlan, e, aí, alguns questionamentos emergem: Seria o implante coclear a única possibilidade de felicidade àqueles que nascem surdos? O que pensam as famílias que têm seus filhos surdos não implantados? Estaríamos tratando de um processo de convencimento dos benefícios trazidos pelo implante coclear?

Tais perguntas nos permitem diferentes elaborações discursivas, mas, se forem observadas pelo viés cultural, as possíveis respostas àquilo que é problematizado seguem na lógica de compreender "a surdez como um traço cultural", de forma que "não significa retirá-lo do corpo, negando seu caráter 'natural". "Significa aqui pensar dentro de um campo em que sentidos são construídos em um coletivo que se mantém por aquilo que inscreve sobre a superfície de um corpo" (LOPES, 2011, p. 16).

Mas, as discussões extrapolam a concepção de corpo, mesmo que este esteja diretamente aqui implicado - um corpo de intensidades, um corpo em crise. A crise da surdez (?). Entendemos que nesta discussão "estão implicadas formas de se relacionar, formas de se identificar com alguns e se distanciar de outros, formas de se comunicar e de utilizar a visão como um elo aproximador entre sujeitos semelhantes" (LOPES, 2011, p. 23).

A surdez passa a ser marcada "pela presença de um conjunto de elementos que inscrevem alguns sujeitos em um grupo, enquanto que outros são deixados de fora desse grupo" (LOPES, 2011, p. 23). Os implantados e os não implantados. Os normais/normalizados e os anormais. Os desejados e os indesejados. Aqueles que desejam o lugar de surdo implantado e aqueles que o repudiam entendendo o mesmo como uma agressão ao corpo surdo. 
Neste corpo as tensões e diferenciações são inventadas e experimentadas a todo instante visualizando seus limites, possibilidades e suas próprias percepções sobre seu corpo. Suas lutas (sejam elas a favor ou contra o implante coclear) parecem tratar de condições de vida e de comunicação. Assim, o corpo "é uma construção, uma instância de conexão, um terminal, um objeto transitório e manipulável de muitos emparelhamentos" (LE BRETON, 2009, p. 128).

Em uma linha de proximidade/familiaridade, a reportagem apresenta um caso parecido no Brasil - o caso de Manu (Taubaté-SP). “- Hoje ela tem 11 anos, mas fez o implante coclear quando tinha um pouco mais de 1 ano de idade. A emoção no momento de ativação do aparelho também foi grande". Como via ilustrativa de tal emoção, as imagens que se seguem à fala da repórter se assemelham às imagens do menino Lachlan, transmitindo uma sensação de felicidade da criança com a ativação do aparelho. O corpo é o primeiro e mais natural instrumento de manipulação (MAUS, 2003).

Nas sociedades ocidentais em geral, a tecnologia estabelece, cada vez mais, estreitas relações com os corpos, e os objetos técnicos são literalmente incorporados. Assim, as próteses e implantes são como uma realidade discursiva geradora e produtora de novas relações, conforme padrões técnicos, na base de valores específicos, científicos. "O implante, como um computador. Um objeto frio, rígido, digital a ser incrustado na pele quente, mole e úmida. [...] com uma junção que pode permanentemente machucar corpo-cérebro, ouvido, violados pela linguagem forasteira de zuns e zeros" (CHOROST, 2005, p. 8). Nesse contexto, o corpo é anatomizado pela legitimidade do discurso científico da biomedicina. O corpo se converte na fronteira que marca a diferença entre um corpo normalizado e outro anormalizado.

A referência aos casos existentes também no Brasil tem uma possível intencionalidade de aproximação, familiaridade e via de acesso facilitado àqueles que se sintam interessados na realização do implante coclear. O sujeito passa a ocupar-se de um lugar geralmente de felicidade plena, experimentando emoções até então desconhecidas e somente alcançáveis por meio da audição.

Tratamos de possíveis estratégias de controle e normalização, "cujo foco é o controle pormenorizado dos corpos, que devem se fazer dóceis e úteis" (FISCHER, 2012, p. 59). O controle, conseguido por meio do implante coclear, pode trazer a docilidade e fácil relacionamento (em termos de comunicação e língua) com os demais, afirmando a necessidade e benefícios da realização do mesmo. Aí, o implante parece ser apresentado como via de "docilização do corpo" (VEIGA-NETO, 2011, p. 65).

Estes, os $\mathrm{CsO}$, ou mesmo os corpos surdos, são desejos, corpos-desejos. "É ele e por ele que se deseja", pois, "o desejo vai até aí: às vezes desejar seu próprio aniquilamento, às vezes desejar aquilo que tem o poder de aniquilar” (DELEUZE; GUATTARI, 2012, p. 32). Aniquilamento da surdez, do implante coclear ou da possibilidade de transformar-se em um ouvinte (?).

Dentre as possibilidades existentes, aquelas que parecem ser visibilizadas pela referida notícia se aproximam das três opções acima apontadas. A mãe da menina 
relata: “- Aí houve esse período de ensinar para a Manuela o sentido do som”. E sua fala é seguida por filmagens caseiras, quando é possível ver a mãe realizando brincadeiras nas quais pergunta para a filha o nome de alguns animais e também brinca com os numerais.

No geral, as falas e imagens parecem apresentar um aprendizado tranquilo, familiar e feliz, sem prejuízos à criança, preocupações familiares ou mesmo alterações na rotina dos mesmos. O sujeito, pela via do implante coclear, normaliza a rotina familiar, eliminando as possíveis dificuldades enfrentadas pela surdez.

A repórter segue apresentando a história da menina (Manu): “- E nesse processo a Manu se apaixonou por música [...], depois vieram as aulas de teatro [...].E o que você sonha para o seu futuro? - Eu sonho em ser atriz!"

Refere-se aqui às possibilidades da música e do teatro vinculadas a sua capacidade de escutar, diferenciando sujeitos implantados (capazes de realizar atividades de música e teatro) daqueles que não o são (tratados aqui como incapazes de realizar o mesmo). A menina implantada e feliz, graças ao implante, pode, agora, ter uma vida normal e, inclusive, sonhos para o futuro. A norma é atendida e se visibiliza nas cenas da menina tocando flauta doce em um parque (em um cenário de tranquilidade e harmonia) e participando das aulas de teatro em interação com a professora e colegas (interagindo de forma oral com os mesmos).

Agora todos seus espaços são conhecidos e ela se torna alcançável. Aquilo que gerava incômodo, desconforto, medo e dificuldades, já não existe mais. A criança surda foi embora e uma ouvinte ocupou-se deste lugar. Eis que agora ela é reconhecida, e um outro rosto ocupa-se dela.

Mais adiante, e ainda na lógica de relatos/histórias de crianças implantadas, a repórter apresenta outro caso (como possível tentativa de afirmar que os casos de crianças implantadas não são raros, mas têm sido bastante comuns e, em uma reportagem de menos de 5 minutos, três casos são apresentados). "- Para o Pedrinho, de 1 ano e 5 meses, a descoberta dos sons do mundo começou nesta semana”.

A fala da repórter também é acompanhada das imagens da criança sorrindo/ emocionando-se ao escutar (pela primeira vez) os sons ao seu redor, ou mesmo das cenas que captam "o exato momento em que crianças que nasceram surdas escutam pela primeira vez". Este momento, segundo o pai do menino, "- Foi impactante, foi muito bonito ver ele ouvindo pela primeira vez. Eu acho que essa imagem fica gravada na gente pro resto da vida".

Aí percebemos a diferença das emoções entre a descoberta da surdez e o momento em que a criança escuta pela primeira vez. O filho não desejado desaparece, dando lugar ao filho ideal, ouvinte, normal. Emoção associada aos padrões de normalidade existentes e constituintes das concepções destes pais. Suas concepções de normalidade se materializam por meio do implante coclear e se visibilizam no momento exato em que a criança demonstra escutar. 
Aproximando-se do desfecho destas histórias, a repórter pergunta aos pais do menino: "-E o que muda na vida do Pedro?” A mãe responde: “-Tudo, muda tudo!" E a repórter encerra: "- Uma mudança que a Manu já conhece bem... Você é feliz Manu?” E a menina responde: “- Aham. Graças a Deus sim”. E a reportagem termina com imagens da menina Manuela brincando feliz em um parque, e do menino Pedro batendo palmas e sorrindo.

O implante coclear ocupa-se do lugar de importantes mudanças na vida da criança e de toda a família, sendo caracterizado como via de alcance da felicidade. Os discursos, assim, reiteram os sujeitos implantados, diferenciando-os daqueles que, porventura, não o foram, pela sua felicidade plena e de seus pais. Aí, os benefícios do implante coclear se materializam nas filmagens caseiras da infância da criança e naquilo que a repórter é capaz de captar no momento da entrevista.

\section{Cadê o surdo que estava aqui? (aquilo que não se diz e não se mostra como linha de apagamento da surdez e invisibili- dade da língua de sinais)}

O material aqui problematizado também se dá por linhas capazes de elaborar o apagamento da surdez e a invisibilidade da língua de sinais. Tais movimentos podem ser percebidos por meio dos relatos dos pais das crianças implantadas mostradas na notícia e também por aquilo que é dito pela repórter (unidade apresentada no subtítulo anterior). Por isso, há uma maior dificuldade de apontar o tempo total destinado a esta unidade discursiva, pois ela compõe e perpassa a notícia em diferentes tempos e de diferentes maneiras.

De qualquer forma, a concepção de surdez visibilizada na notícia analisada parece direcionar-nos a histórias de tristeza, falta e dificuldades. Seu apagamento, de forma distinta, surge como um gesto de contentamento e alegria, ou mesmo da confirmação do(a) filho(a) desejado(a). Aí, as concepções acerca da surdez são construídas nas narrativas sociais e midiáticas, sendo associadas e produzidas no interior de campos discursivos distintos (LOPES, 2011).

Buscamos, no entanto, para além da surdez, olhar e problematizar as diferentes possibilidades de constituir-se (ou não) surdo. Uma intencionalidade de elaboração de uma linha de pensamento sobre os diferentes modos de subjetivação destes indivíduos.

Seus modos de subjetivação se fazem a partir das/pelas unidades discursivas e não discursivas produzidas nos diversos espaços e por diferentes indivíduos. Consideramos uma descontinuidade de práticas surdas, dentre elas aquelas que são veiculadas pelos meios de comunicação, em especial, a televisão.

Em tal descontinuidade, o discurso é alvo de desejo, "aquilo porque, pelo que se luta, o poder do qual nos queremos apoderar” (FOUCAULT, 2013, p. 10). O discurso aparece como via de convencimento e exemplificação das concepções defendidas ou mesmo das linhas que compõem os movimentos midiáticos. 
A repórter afirma: “- $\mathrm{O}$ menino hoje tem dois anos de idade. Ouve e fala bem”. Em seguida (e como possível ilustração e comprovação da afirmativa), é mostrada uma imagem do pai com o filho, na qual o pai questiona: “- O que é isso?”, e o menino responde oralmente: "- Tartaruga”. E o pai afirma: “- Tartaruga. Bom menino”. Eis que a surdez desaparece. O menino agora é capaz de escutar seu pai e responder-lhe oralmente - a forma desejada e aceita pela família e por boa parte da sociedade.

A fala da repórter é facilmente corporificada na cena entre pai e filho. Tão pequeno e já demonstra os resultados alcançados por meio do implante coclear. Um caminho rápido, eficiente e normalizador. A reportagem traz os (não) surdos (aqueles que assim se consideram e aqueles que não) como referentes, buscando diferenciar os implantados daqueles que não o foram, o implante coclear como possibilidade de ocupar um outro lugar, de reposicionar-se, e, ainda, a associação com enunciados de promessas de felicidade no presente e no futuro, como consequência da correção alcançada com o implante coclear.

Tais interfaces discursivas fundamentam-se aqui na concepção de corpo $(\mathrm{CsO})$, de discurso e de modos de subjetivação, na percepção de que estão interligados rizomaticamente. A interligação entre estes conceitos permite-nos afirmar que, ao referirmo-nos aos surdos, estamos tratando de sujeitos híbridos, distintos entre si, em constantes movimentos discursivos e não discursivos, produzidos junto desta trama rizomática traçada pelos discursos midiáticos.

Neste sentido, há de se questionar: Que sujeitos sentem-se implicados por tal reportagem? Como seus discursos permitem a elaboração de outros modos de subjetivação? Ou mesmo, como estes discursos atingem as famílias que possuem filhos surdos não implantados (e possíveis usuários de língua de sinais)?

Os discursos que compõem a referida notícia parecem colocar em xeque práticas e sujeitos que se fazem pela lógica cultural e da língua de sinais. A notícia se firma na lógica da deficiência, podendo ser vista como um convite à realização do implante coclear e à invisibilização (desutilização) da língua de sinais ou, talvez, um convite para outros modos de subjetivação.

Os modos de subjetivação, no entanto, são "aqui entendidos como os mecanismos pelos quais nos tornamos sujeito e ao mesmo tempo assujeitados aos outros e a nós mesmos" (VEIGA-NETO, 2006, p. 81). "A subjetivação como uma prática de liberdade, e não de assujeitamento" (GALLO, 2006, p. 187), ou "os modos através dos quais os sujeitos são produzidos, como assujeitamento e como libertação" (GALLO, 2006, p. 179).

\section{Considerações}

A partir das três unidades discursivas apresentadas, parece-nos que a mesma produz discursos sobre os surdos em uma via de deficiência, localizando-os em um lugar de falta e possível correção, que é alcançada, facilmente, por meio do implante coclear. A língua de sinais é invisibilizada durante a reportagem, sem brechas que 
permitam pensar que surdos podem utilizar a língua de sinais como primeira língua, e que esta é uma língua completa e de igual valia à língua oral do país.

A rede discursiva da reportagem caminha na direção de pensar que surdos podem e precisam ser corrigidos, implantados, e ainda apresentam o implante como "um caminho tranquilo e feliz", por trazer resultados satisfatórios. Tais discursos parecem produzir a crise da surdez e da língua de sinais, na tentativa de normalizar e implantar todos aqueles que são desviantes da norma.

O implante coclear parece surgir como via de acesso à felicidade, ou mesmo à descoberta "maravilhosa nomeada no show da vida", junto ao apagamento da surdez e da criança surda, em uma tentativa de implantar e amenizar a falha. Esse movimento discursivo apresentado na reportagem desenha, assim, outras formas de compreensão do corpo-ouvido-surdo que incluem a complexidade, a incerteza, a reversibilidade, a descoberta.

\section{Referências}

CHOROST, M. Rebuilt: how becoming part computer made me more human. Boston: Houghton Mifflin Company, 2005.

DELEUZE, G.; GUATTARI, F. Mil Platôs - capitalismo e esquizofrenia 2. 2. ed. São Paulo: Editora 34, 2012. Vol. 3.

FANTÁSTICO. O momento em que crianças que nasceram surdas escutam pela primeira vez. Disponível em: <http://globotv.globo.com/rede-globo/fantastico/v/veja-o-momento-emque-criancas-que-nasceram-surdas-escutam-pela-primeira-vez/3614390/>. Acesso em: 14 set. 2014.

FISCHER, R. M. B. Trabalhar com Foucault: arqueologia de uma paixão. Belo Horizonte: Autêntica, 2012.

. Foucault e a análise do discurso em educação. Cadernos de Pesquisa, n. 114, p. 197-223, nov. 2001. Disponível em: <http://www.scielo.br/pdf/cp/n114/a09n114.pdf $>$. Acesso em: 29 ago. 2014.

FOUCAULT, M. A ordem do discurso: aula inaugural no Collége de France, pronunciada em 2 de dezembro de 1970. 23. ed. São Paulo: Edições Loyola, 2013.

GALLO, S. Cuidar de si e cuidar do outro: implicações éticas para a educação dos últimos escritos de Foucault. In: GONDRA, J.; KOHAN, W. (Orgs.). Foucault 80 anos. Belo Horizonte: Autêntica, 2006. p. 177-189.

LE BRETON, D. As paixões ordinárias: antropologia das emoções. Petrópolis: Vozes, 2009. $276 \mathrm{p}$.

LOPES, M. C. Surdez \& educação. 2. ed. Belo Horizonte: Autêntica Editora, 2011.

MAUSS, M. Sociologia e antropologia. São Paulo: Cosac \& Naify, 2003.

ROSE, N. Inventando nossos selfs: psicologia, poder e subjetividade. Petrópolis, RJ: Vozes, 2011.

SCHWENGBER, M. S. V. Donas de si? Educação de corpos grávidos no contexto da Pais \& Filhos. Porto Alegre: UFRGS, 2006, 192f. Tese [Doutorado em Educação]- Programa de Pós-Graduação em Educação. Faculdade de Educação, Universidade Federal do Rio Grande do Sul, Porto Alegre, 2006. 
VEIGA-NETO, A. Na oficina de Foucault. In: GONDRA, J.; KOHAN, W. (Orgs.). Foucault 80 anos. Belo Horizonte: Autêntica, 2006. p. 79-91.

Foucault \& educação. 3. ed. Belo Horizonte: Autêntica Editora, 2011.

\section{Notas}

${ }^{1}$ DELEUZE; GUATTARI (2012); FOUCAULT (2013).

${ }^{2}$ Corpo sem Órgãos (DELEUZE; GUATTARI, 2012).

* Doutoranda em Educação nas Ciências pela Universidade Regional do Noroeste do Estado do Rio Grande do Sul, Ijuí, Rio Grande do Sul, Brasil.

** Professora doutora da Universidade Regional do Noroeste do Estado do Rio Grande do Sul, Ijuí, Rio Grande do Sul, Brasil.

\section{Correspondência}

Daniela Medeiros - Universidade Regional do Noroeste do Estado do Rio Grande do Sul, Câmara de Graduação. Rua do Comércio, Universitário, CEP: 98700-000, Ijuí, Rio Grande do Sul - Brasil.

E-mail: danimedeiros10@yahoo.com.br - simone@unijui.edu.br

Recebido em 30 de abril de 2015

Aprovado em 09 de novembro de 2015 